\title{
Measuring the relative efficiency of banks using DEA method
}

\author{
Mohammad Reza Ghaeli ${ }^{\text {a* }}$
}

\begin{tabular}{l}
${ }^{\mathrm{a} F a c u l t y}$ of Computer Studies and Infor \\
\hline C H R O N I C L E \\
\hline Article history: \\
Received September 5, 2016 \\
Received in revised format \\
November 112016 \\
Accepted January 202016 \\
Available online \\
January 23 2017 \\
\hline Keywords: \\
Data envelopment analysis \\
(DEA) \\
Efficiency \\
Bank Industry
\end{tabular}

\begin{abstract}
A B S T R A C T
Data Envelopment Analysis (DEA) is one of the most popular methods used for measuring the relative efficiency of similar units by considering various input/output parameters. This paper implements DEA models to estimate the relative efficiency of selected banks in the United States. The proposed study uses two inputs, total assets and number of employees, and one output, net revenue for measuring the relative efficiency of selected banks. The relative efficiencies of different banks are analyzed. The preliminary results indicate that Santander Bank is the most efficient banks operating in the United States followed by SunTrust Bank and HSBC. Other banks preserve lower efficiency compared with these three banks.
\end{abstract}

\section{Introduction}

Measuring the relative efficiency of banks is one of the primary concerns for making any investment decisions. Data envelopment analysis (DEA) is one of the most efficient techniques for measuring the relative efficiency of similar units; e.g. banks, insurance firms, etc. (Fallah et al., 2011). The benefit of applying DEA is that one may apply the non-financial factors such as the number of employees along with the financial data to have a fair comparison of various units. DEA is one of the methods to use for such purpose. During the past several years, there has been substantial interest on applying DEA techniques for calculating the relative efficiency of banks around the world (Haslem et al., 1999; Mercan et al., 2003). Yang et al. (2010) applied an integrated bank performance measurement and management planning using hybrid minimax reference point - DEA approach.

Staub et al. (2010) investigated various factors influencing the relative efficiency of Brazilian banks such as cost and technical efficiencies from 2000 to 2007. They stated that Brazilian banks influenced from low levels of efficiency compared with European or North American ones. They also stated that state-owned banks were substantially more cost efficient than other alternative foreign banks. Nevertheless, they did not report any evidence to show that the differences in economic efficiency were

* Corresponding author.

E-mail address: rghaeli@nyit.edu (M. R. Ghaeli) 
because of the type of activity and bank size. Avkiran (2010) investigated the relationship between the supper-efficiency estimations and some other key financial ratios for some Chinese banking sector. They provided some opportunity to determine the inefficient units where there was a low cooperation between the supper-efficiency and good financial ratios. Lin et al. (2009) executed various DEA techniques for 117 branches of a certain banks in Taiwan and stated an overall efficiency of 54.8 percent for all units. They also showed that most branches were relatively inefficient. Thoraneenitiyan and Avkiran (2009) investigated the implementation of a combined DEA and SFA to measure the effect of restructuring and country-specific factors on the efficiency of post-crisis East Asian banking systems over the period 1997-2001. They stated that banking system inefficiencies were primarily attributed to country-specific circumstances, such as high interest rates, concentrated markets and economic development. DEA was also implemented for banking decisions. For example, Che et al. (2010) applied a combination of Fuzzy analytical hierarchy procedure (AHP) and DEA as a decision making facility for making decisions on loan assignments.

This paper is organized as follows. We first provide the problem statement of DEA method in section 2. Section 3 gives an in-depth discussion of various DEA models for input and output estimation together with efficiency improvement and mathematical calculation methods. We provide the implementation of the DEA approach for banking sector in section 4. Finally, concluding remarks are given in the last section to summarize the contribution of the paper.

\section{Data Envelopment Analysis}

The constant return to scale DEA (CCR) was first proposed by Charnes, et al. $(1978,1994)$ as a mathematical technique for measuring the relative efficiency of decision making units (DMU). One may easily learn how a given DMU works whenever a production function becomes available. Nevertheless, in some cases reaching an analytical form for this function may not be possible. Thus, we form a set of production feasibility, which consists of some principles such as fixed-scale efficiency, convexity and feasibility as follows,

$$
T_{C}=\left\{(X, Y) \mid X \geq \sum_{j=1}^{n} \lambda_{j} X_{j}, Y \leq \sum_{j=1}^{n} \lambda_{j} Y_{j}, \lambda_{j} \geq 0, j=1, \cdots n\right\},
$$

where $X$ and $Y$ represent the input/output vectors, respectively. The CCR production feasibility set border describes the relative efficiency in which any off-border DMU is stated as inefficient. The CCR model can be measured in two types of either input or output oriented. The input CCR plans to decrease the maximum input level with a ratio of $\theta$ so that, at least, the same output is generated, i.e.:

$$
\begin{aligned}
& \min \quad \theta \\
& \text { subject to } \\
& \theta X_{p}-\sum_{j=1}^{n} \lambda_{j} X_{i j} \geq 0, \\
& \sum_{j=1}^{n} \lambda_{j} Y_{r j} \geq Y_{r p}, \\
& \lambda_{j} \geq 0, \quad j=1, \cdots, n .
\end{aligned}
$$

Model (2) is called envelopment form of input CCR where $\theta$ is the relative efficiency of the DMU and it is an easy assignment to show that the optimal value of $\theta, \theta^{*}$, is always between zero and one (Fallah et al., 2011). For the input oriented DEA one, once the efficiency of a DMU unit, $D M U_{p}$, reduces in case of inefficiency, one may directs it towards the border to make it efficient. In the case of the output oriented DEA model, the primary objective is to maximize the output level, $\varphi$, by applying the same amount of input (Fallah et al., 2011). The model can be formulated as follows, 
$\min \varphi$

subject to

$\sum_{j=1}^{n} \lambda_{j} X_{i j} \leq X_{i p}$,

$\sum_{j=1}^{n} \lambda_{j} Y_{j} \geq \varphi Y_{i p}$

$\lambda_{j} \geq 0, \quad j=1, \cdots, n$.

\section{DEA Models for Estimating and Improving Inputs and Outputs}

\subsection{Output estimation}

Consider $n$ various DMUs as $\left\{D M U_{j}: j=1, \ldots, n\right\}$ using $m$ inputs to generate $s$ outputs. Let $y_{r i}$ and $x_{i j}$ be the $r$ th output, $r=(1, \cdots, s)$ and the $i$ th input, $i=(1, \cdots m)$ of the $j$ th DMU, $j=(1, \cdots n)$, respectively (Fallah et al., 2011). Consider $\varphi^{*}$ as the efficiency level of the $\mathrm{DMU}_{\mathrm{p}}$ where it has a value of one or higher, i.e. the measured unit is either efficient or inefficient (Fallah et al., 2011). Suppose that we increase the inputs of $\mathrm{DMU}_{\mathrm{p}}$ from $x_{\mathrm{p}}$ to $\alpha_{i p}=x_{i p}+\Delta x_{i p}$ where $\Delta x_{p} \geq 0$ and $\Delta x_{p} \neq 0$ and we wish to learn how much output $\mathrm{DMU}_{\mathrm{p}}$ could be produced. That is we wish to estimate the output vector $y_{r p(\text { new })}=\left(y_{1 p(\text { new })}, y_{2 p(\text { new })}, \ldots y_{s p(n e w)}\right)$, where we present them as $\beta_{r p}=\left(\beta_{1 p}, \beta_{2 p}, \ldots \beta_{s p}\right)$, for the sake of the simplicity. We also look at two conditions for the problem statement. First, we assume that as the inputs increase, $\varphi^{*}$ remains unchanged and second, as the inputs increase the efficiency will also increase too. If efficiency increase is not the target and the efficiency of $\mathrm{DMU}_{\mathrm{p}}$ remains at $\varphi^{*}$, the outputs of the measured unit can be calculated by solving the following (Fallah et al., 2011),

$$
\begin{aligned}
& \max \quad \beta_{p}=\left(\beta_{1 p}, \cdots, \beta_{s p}\right) \\
& \text { subject to } \\
& \sum_{j=1}^{n} \lambda_{j} X_{i j} \leq \alpha_{i p} \\
& \sum_{j=1}^{n} \lambda_{j} Y_{r j} \geq \varphi_{p}^{*} \beta_{p} \\
& \beta_{p} \geq Y_{p} \\
& \lambda_{j} \geq 0 \quad j=1 \ldots n .
\end{aligned}
$$

Model (4) is a multi-purpose problem to solve where we assign weights $\left(w_{p}\right)$ to each output $\left(y_{i p}\right)$ based on a multiple criteria decision making methods such as AHP. Let

$\beta_{r p}=\left(\beta_{1 p}, \beta_{2 p}, \ldots \beta_{s p}\right)=\sum_{r=1}^{s} w_{r} \beta_{r p}$. Therefore,

$$
\max \quad \beta_{p}=\left(\beta_{1 p}, \cdots, \beta_{s p}\right)=\sum_{r=1}^{s} w_{r} \beta_{r p}
$$

subject to

$$
\begin{aligned}
& \sum_{j=1}^{n} \lambda_{j} X_{i j} \leq \alpha_{i p} \\
& \sum_{j=1}^{n} \lambda_{j} Y_{r j} \geq \varphi_{p}^{*} \beta_{p} \\
& \beta_{p} \geq Y_{p} \\
& \lambda_{j} \geq 0 \quad j=1 \ldots n .
\end{aligned}
$$


Let $\Delta x_{p}$ be the increase on the inputs of unit $p$ and $\eta$ be the percentage of the increase on $\varphi^{*}$. In order to reach the output for unit $p$ we replace $\varphi^{*}$ with $\left(1-\frac{\eta}{100}\right) \varphi^{*}$ in $(5)$ which gives,

$$
\begin{aligned}
& \max \quad \beta_{p}=\left(\beta_{1 p}, \cdots, \beta_{s p}\right)=\sum_{r=1}^{s} w_{r} \beta_{r p} \\
& \text { subject to } \\
& \sum_{j=1}^{n} \lambda_{j} X_{i j} \leq \alpha_{i p}, \\
& \sum_{j=1}^{n} \lambda_{j} Y_{r j} \geq\left[(1-\eta / 100) \varphi_{p}^{*}\right] \beta_{p}, \\
& \beta_{p} \geq Y_{p}, \\
& \lambda_{j} \geq 0 \quad j=1 \ldots n .
\end{aligned}
$$

\subsection{Input estimation}

Let $\theta^{*}$ be the optimal efficiency value of the DMU measured by model (2) and we wish to increase the production of $\mathrm{DMU}_{\mathrm{p}}$ by $\Delta y_{p} \geq 0$, that is $y_{r p(n e w)}=\beta_{r p}=y_{r p}+\Delta y_{r p}$. Assuming a constant efficiency of the measured DMU we can estimate the inputs of the unit $p$ with similar method stated in the previous section. Let $x_{i p(\text { new })}=\left(x_{1 p(\text { new })}, x_{2 p(\text { new })}, \ldots x_{m p(n e w)}\right)=\alpha_{i p}=\left(\alpha_{1 p}, \alpha_{2 p}, \ldots \alpha_{m p}\right)$ and to simplify the solution of the multi-purpose function, one could rewrite the target function as $\alpha_{i p}=\left(\alpha_{1 p}, \alpha_{2 p}, \ldots \alpha_{m p}\right)=\sum_{i=1}^{m} w_{i} \alpha_{i p}$ and solve the following model (Fallah et al., 2011),

$$
\min \quad \alpha_{i p}=\left(\alpha_{1 p}, \alpha_{2 p}, \ldots \alpha_{m p}\right)=\sum_{i=1}^{m} w_{i} \alpha_{i p}
$$

subject to

$$
\begin{aligned}
& \sum_{j=1}^{n} \lambda_{j} X_{i j} \leq \theta^{*} \alpha_{i p} \quad i=1 \ldots m \\
& \sum_{j=1}^{n} \lambda_{j} Y_{r j} \geq \beta_{r p} \quad r=1 \ldots s \\
& \alpha_{i p} \geq x_{i p} \\
& \lambda_{j} \geq 0 \quad j=1 \ldots n .
\end{aligned}
$$

Let $\delta$ be the percentage increase in efficiency of $\theta^{*}$ resulted when the outputs are increased. Let $\theta^{*}$ is replaced with $\left(1+\frac{\delta}{100}\right) \theta^{*}$. Therefore, we have,

$$
\min \alpha_{i p}=\left(\alpha_{1 p}, \alpha_{2 p}, \ldots \alpha_{m p}\right)=\sum_{i=1}^{m} w_{i} \alpha_{i p}
$$

subject to

$$
\begin{aligned}
& \sum_{j=1}^{n} \lambda_{j} X_{i j} \leq(1+\delta / 100) \theta^{*} \alpha_{i p} \quad i=1 \ldots m \\
& \sum_{j=1}^{n} \lambda_{j} Y_{r j} \geq \beta_{r p} \quad r=1 \ldots s \\
& \alpha_{i p} \geq x_{i p} \\
& \lambda_{j} \geq 0 \quad j=1 \ldots n .
\end{aligned}
$$


Nevertheless, if the amount of efficiency increase is not given and the measured organization needs such increase as a precondition for increase in the outputs, then the input estimation of model (7) will be changed to model (8) where $\theta \geq \theta^{*}$ is an additional condition.

\section{Analysis and Results}

In this section, we present the details of our DEA implementation for measuring the relative efficiency of selected banks operating in the United States. The data for the input and the output are collected for the fiscal year of 2016. The study uses two inputs and one output shown in Fig. 1.

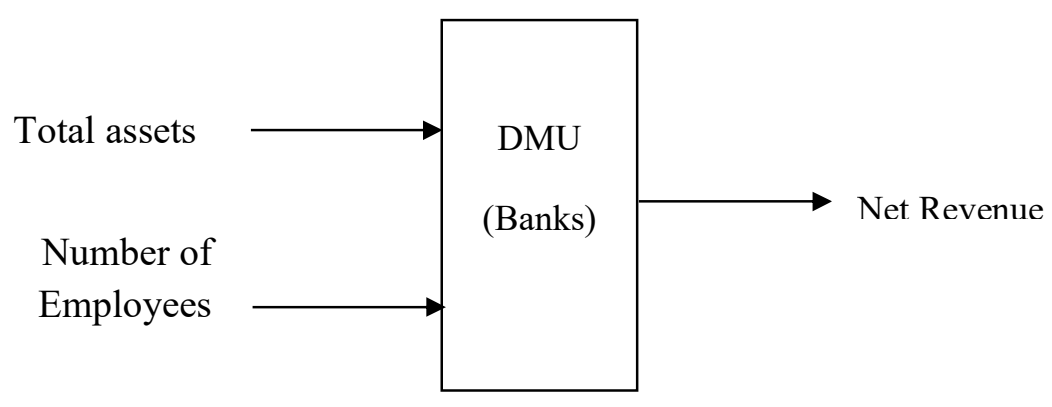

Fig. 1. The input and the output of DEA model

The input data for all 26 units are summarized in Table 1 where the second column represents total assets, the third column shows the number of employees, the fourth column represents the net revenue and finally, and finally the relative efficiency of all units are given in the last column.

\section{Table 1}

The results of the implementation of DEA method

\begin{tabular}{|c|c|c|c|c|}
\hline \multirow[b]{2}{*}{ Name } & \multicolumn{2}{|c|}{ Inputs } & \multirow{2}{*}{$\begin{array}{c}\text { Output } \\
\text { Net revenue (Millions) }\end{array}$} & \multirow[b]{2}{*}{ Efficiency } \\
\hline & Total Assets (Billions) & Number of Employee & & \\
\hline Santander Bank & $\$ 126$ & 9,525 & 7,967 & 1 \\
\hline SunTrust Bank & $\$ 198$ & 24,00 & 1,933 & 0.962921 \\
\hline HSBC & $\$ 295$ & 266,273 & 15,096 & 0.809311 \\
\hline American Express & $\$ 159$ & 54,000 & 5,163 & 0.513548 \\
\hline TD Bank & $\$ 276$ & 85,000 & 6,133 & 0.351431 \\
\hline Ally Financial & $\$ 157$ & 7,100 & 1,289 & 0.217053 \\
\hline U.S. Bancorp & $\$ 438$ & 67,000 & 5,879 & 0.212278 \\
\hline Goldman Sachs & $\$ 896$ & 34,800 & 6,083 & 0.208982 \\
\hline BMO Harris Bank & $\$ 132$ & 14,500 & 1,712 & 0.205119 \\
\hline Wells Fargo & $\$ 1,889$ & 264,700 & 22,894 & 0.191675 \\
\hline Fifth Third Bank & $\$ 143$ & 21,613 & 1,712 & 0.189341 \\
\hline Capital One & $\$ 339$ & 45,400 & 4,050 & 0.188943 \\
\hline PNC Bank & $\$ 361$ & 52,500 & 4,106 & 0.179882 \\
\hline JPMorgan Chase & $\$ 2,466$ & 246,303 & 24,442 & 0.156754 \\
\hline Citigroup & $\$ 1,818$ & 239,000 & 17,242 & 0.149993 \\
\hline BB\&T & $\$ 221$ & 39,000 & 2,084 & 0.149136 \\
\hline M\&T Bank & $\$ 123$ & 16,331 & 1,065 & 0.136937 \\
\hline Bank of New York & $\$ 372$ & 51,200 & 3,158 & 0.13426 \\
\hline Regions Bank & $\$ 126$ & 23,000 & 1,062 & 0.1333 \\
\hline Morgan Stanley & $\$ 828$ & 55,802 & 6,127 & 0.131271 \\
\hline Northern Trust & $\$ 121$ & 16,500 & 973.8 & 0.12728 \\
\hline Charles Schwab & $\$ 198$ & 14,000 & 1447 & 0.123569 \\
\hline State Street & $\$ 255$ & 33,332 & 1,980 & 0.122801 \\
\hline Bank of America & $\$ 2,186$ & 210,516 & 15,888 & 0.114946 \\
\hline Citizens Bank & $\$ 145$ & 17,852 & 840 & $9.16 \mathrm{E}-02$ \\
\hline RBC Bank & $\$ 151$ & 72,839 & 143 & $1.50 \mathrm{E}-02$ \\
\hline
\end{tabular}


As we can observe from the results of Table 1, Santander Bank is the most efficient banks operating in the United States followed by SunTrust Bank and HSBC. Other banks preserve lower efficiency compared with these three banks. These banks may reduce the number of their employees or reduce their physical equipment to increase their efficiencies.

\section{Conclusion}

In this paper, we have presented an empirical investigation to measure the relative efficiency of some selected banks in the United States using a well-known method named data envelopment analysis. The proposed study has considered the banks' employees and equipment as input and net revenue as the output. The results have indicated that most banks in United States have performed poorly and must reduce their employees or make some changes on their physical equipment.

\section{Acknowledgement}

The authors would like to thanks the anonymous referees for constructive comments on earlier version of this paper.

\section{References}

Charnes A, Cooper, W. W., Rhodes, E. (1978). Measuring the efficiency of decision making units. European Journal of the Operational Research, 2, 429-44.

Charnes A, Cooper W. W., Lewin, A., Seiford, L. M. (1994). Data envelopment analysis: theory, methodology and applications. Massachusetts: Kluwer Academic Publishers.

Fallah, M., Aryanechad, M.B., Najafi, S.E., \& Shahsavaripour, N. (2011). An empirical study on measuring the relative efficiency using DEA method: A case study of bank industry. Management Science Letters, 1(1), 49-56.

Staub, R. B., Da Silva e Souza, G. \& Tabak, B. M. (2010). Evolution of bank efficiency in Brazil: A DEA approach. European Journal of Operational Research, 202(1), 204-213.

Avkiran, N. K. (2010). Association of DEA super-efficiency estimates with financial ratios: Investingating the case for Chinese banks. Omega, doi:10.1016/j.omega.2010.08.001.

Lin, T. T., Lee, Ch-Ch., \& Chiu, T-F. (2009). Application of DEA in analyzing a bank's operating performance. Expert Systems with Applications, 36(5), 8883-8891.

Yang, J.B., Wong, B.Y.H., Xu, D.L., Liu, X.B. \& Steuer, R.E. (2010). Integrated bank performance assessment and management planning using hybrid minimax reference point - DEA approach. European Journal of Operational Research, doi:10.1016/j.ejor.2010.07.001.

Thoraneenitiyan, N., \& Avkiran, N. K. (2009). Measuring the impact of restructuring and countryspecific factors on the efficiency of post-crisis East Asian banking systems: Integrating DEA with SFA. Socio-Economic Planning Sciences, 43(4), 240-252.

Che, Z. H., Wang, H. S., \& Chuang, Ch-L. (2010). A fuzzy AHP and DEA approach for making bank loan decisions for small and medium enterprises in Taiwan, Expert Systems with Applications, 37(10), 7189-7199.

Mercan, M., Reisman, A., Yolalan, R., \& Burak Emel, A. (2003). The effect of scale and mode of ownership on the financial performance of the Turkish banking sector: results of a DEA-based analysis, Socio-Economic Planning Sciences, 37(3), 185-202.

Haslem, J. A., Scheraga, C. A., \& Bedingfield, J. P. (1999). DEA efficiency profiles of U.S. banks operating internationally. International Review of Economics \& Finance, 8(2), 165-182.

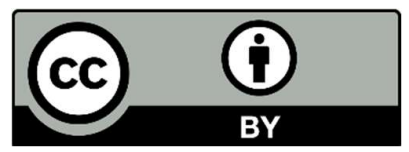

(C) 2017 by the authors; licensee Growing Science, Canada. This is an open access article distributed under the terms and conditions of the Creative Commons Attribution (CC-BY) license (http://creativecommons.org/licenses/by/4.0/). 